\title{
First report of 90-day support of 2 calves with a continuous-flow total artificial heart
}

\author{
Jamshid H. Karimov, MD, PhD, ${ }^{a}$ Nader Moazami, MD, ${ }^{\text {ab }}$ Mariko Kobayashi, MD, ${ }^{\text {a }}$ Shiva Sale, MD, \\ Kimberly Such, DVM, ${ }^{\mathrm{d}}$ Nicole Byram, BS, ${ }^{\mathrm{a}}$ Gengo Sunagawa, MD, ${ }^{\mathrm{a}}$ David Horvath, MSME, \\ Shengqiang Gao, PhD, ${ }^{\mathrm{a}}$ Barry Kuban, BS, ${ }^{\mathrm{a}}$ Leonard A. R. Golding, MB, BS, FRACS, ${ }^{\mathrm{a}}$ and \\ Kiyotaka Fukamachi, MD, $\mathrm{PhD}^{\mathrm{a}}$
}

\begin{abstract}
Objective: The Cleveland Clinic continuous-flow total artificial heart (CFTAH) is a compact, single-piece, valveless, pulsatile pump providing self-regulated hemodynamic output to left/right circulation. We evaluated chronic in vivo pump performance, physiologic and hemodynamic parameters, and biocompatibility of the CFTAH in a well-established calf model.
\end{abstract}

Methods: CFTAH pumps have been implanted in 17 calves total. Hemodynamic parameters, pump performance, and device-related adverse events were evaluated during studies and at necropsy.

Results: In vivo experiments demonstrated good hemodynamic performance (pump flow, $7.3 \pm 0.7 \mathrm{~L} / \mathrm{min}$; left atrial pressure, $16 \pm 3 \mathrm{~mm} \mathrm{Hg}$; right atrial pressure, $17 \pm 3 \mathrm{~mm} \mathrm{Hg}$; right atrial pressure-left atrial pressure difference, $1 \pm 2 \mathrm{~mm}$ $\mathrm{Hg}$; mean arterial pressure, $103 \pm 7 \mathrm{~mm} \mathrm{Hg}$; arterial pulse pressure, $30 \pm 11 \mathrm{~mm}$ $\mathrm{Hg}$; and pulmonary arterial pressure, $34 \pm 5 \mathrm{~mm} \mathrm{Hg}$ ). The CFTAH has operated within design specifications and never failed. With ever-improving pump design, the implants have shown no chronic hemolysis. Three animals with recent CFTAH implantation recovered well, with no postoperative anticoagulation, during planned in vivo durations of 30, 90, and 90 days (last 2 were intended to be 90 day studies). All these longest-surviving cases showed good biocompatibility, with no thromboembolism in organs.

Conclusions: The current CFTAH has demonstrated reliable self-regulation of hemodynamic output and acceptable biocompatibility without anticoagulation throughout 90 days of chronic implantation in calves. Meeting these milestones is in accord with our strategy to achieve transfer of this unique technology to human surgical practice, thus filling the urgent need for cardiac replacement devices as destination therapy. (J Thorac Cardiovasc Surg 2015;150:687-93)

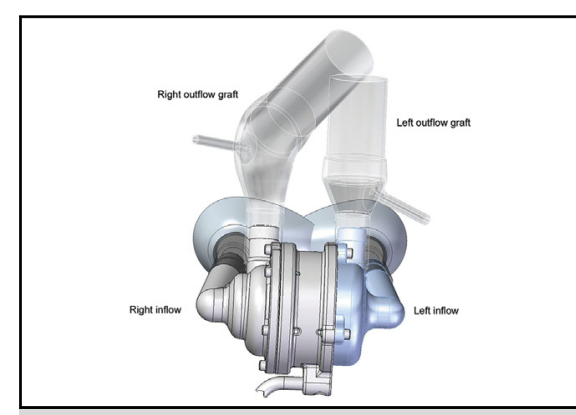

Cleveland Clinic single-piece continuous-flow total artificial heart.

Central Message

In vivo studies showed optimal hemodynamic performance and self-regulation of the singlepiece CFTAH for 90-day duration.

\section{Perspective}

The successful 90-day implants with a singlepiece continuous flow total artificial heart showed optimal hemodynamic output and biocompatibility without anticoagulation. The achievement of this important milestone suggests that reliable, single-piece, autoregulated, and sensorless devices have potential to further develop into a valid clinical option for human patients with heart failure.

See Editorial Commentary page 694

\footnotetext{
From the ${ }^{\mathrm{a}}$ Department of Biomedical Engineering, Lerner Research Institute, ${ }^{b}$ Department of Thoracic and Cardiovascular Surgery, Kaufman Center for Heart Failure, Cardiac Transplantation and Mechanical Circulatory Support, Miller Family Heart and Vascular Institute, ${ }^{\mathrm{c} D e p a r t m e n t}$ of Cardiothoracic Anesthesiology, Anesthesiology Institute, and ${ }^{\mathrm{d}}$ Biological Resources Unit, Lerner Research Institute, Cleveland Clinic, Cleveland, Ohio.

This work was supported by federal funding obtained by L.A.R.G. and K.F. from the National Heart, Lung, and Blood Institute of the National Institutes of Health, under grant No. 5R01HL096619.

Received for publication March 2, 2015; revisions received May 13, 2015; accepted for publication June 4, 2015; available ahead of print July 11, 2015.

Address for reprints: Kiyotaka Fukamachi, MD, PhD, Department of Biomedical Engineering/ND20, Cleveland Clinic, 9500 Euclid Ave, Cleveland, OH 44195 (E-mail: fukamak@ccf.org).

$0022-5223 / \$ 36.00$

Copyright (C) 2015 by The American Association for Thoracic Surgery

http://dx.doi.org/10.1016/j.jtcvs.2015.06.023
}

丹 Supplemental material is available online.

Heart failure (HF) is a serious health care issue and a primary contributor to cardiovascular mortality affecting about 23 million people worldwide, ${ }^{1,2}$ and the prevalence of HF is rising rapidly even in developing nations. ${ }^{3}$ Heart transplantation can provide a remarkable improvement in quality of life and survival in selected patients with endstage $\mathrm{HF}^{4,5}$ but a shortage of donor hearts will always limit this option. Today, hemodynamic support is mainly 


$$
\begin{aligned}
& \text { Abbreviations and Acronyms } \\
& \begin{aligned}
\text { CPB } & =\text { cardiopulmonary bypass } \\
\text { CF } & =\text { continuous flow } \\
\text { CFTAH } & =\text { continuous-flow total artificial heart } \\
\text { HF } & =\text { heart failure } \\
\text { LAP } & =\text { left atrial pressure } \\
\text { LVAD } & =\text { left ventricular assist device } \\
\text { POD } & =\text { postoperative day } \\
\text { RAP } & =\text { right atrial pressure } \\
\text { TAH } & =\text { total artificial heart }
\end{aligned}
\end{aligned}
$$

provided by left ventricular assist devices (LVADs) for transplant-eligible patients and those who fail to meet criteria for heart transplant. ${ }^{5}$

During the past several years, continuous-flow (CF) rotary pumps have replaced volume-displacement pulsatile-flow pumps because of their simplicity, increased mechanical reliability, improved durability, smaller size, and better outcomes. $^{6}$ All (100\%) LVADs implanted in 2012 and 2013 were CF LVADs, ${ }^{7}$ which clearly indicates the future direction of this therapy. However, up to $44 \%$ of patients needing LVADs also have significant right ventricular failure, ${ }^{8}$ for which the only feasible solutions are heart transplantation, biventricular assist devices, or a total artificial heart (TAH). In contrast to LVADs, existing clinical TAHs are all volume-displacement pulsatile-flow pumps: a temporary pneumatic system (CardioWest; SynCardia, Tucson, Ariz), a permanent totally implantable system (AbioCor; Abiomed, Danvers, Mass), and a permanent electrohydraulically driven system (Carmat TAH; Carmat, Vélizy Villacoublay, France). Of significant concern are the large size and questionable durability of these TAHs.

The Cleveland Clinic has developed a unique singlepiece, valveless, continuous-flow total artificial heart (CFTAH) that achieves passive, sensorless autoregulation of pump flows and filling pressures by varying relative left and right pump efficiencies, based on the position of its single moving part, to balance the left and right pump filling pressures and pump outputs. This device uses a single, centrally located, rotating assembly that has impellers for both left and right centrifugal pumps. ${ }^{9,10}$ The position of the centrally located rotating assembly is primarily determined by the differential force between the right and left pump filling pressures acting on this part. In this article, we present the first report on pump performance, physiologic and hemodynamic parameters, and biocompatibility of the single-piece CFTAH in chronic in vivo studies throughout 90 days postimplant.

\section{MATERIALS AND METHODS}

From October 2011 to November 2014, the Cleveland Clinic CFTAH was implanted in 17 calves (Jersey calves; weight range, 77.0-93.9 kg) through a median sternotomy $(\mathrm{n}=9)$ or a right thoracotomy $(\mathrm{n}=8)$ for elective chronic implantation of 14,30 , or 90 days.

The CFTAH passively self-balances left and right circulations without electronic intervention. The nominal external dimensions of the latest CFTAH design used in these studies are $98.4 \mathrm{~mm}$ (length), $62 \mathrm{~mm}$ (diameter), $160 \mathrm{cc}$ (volume displacement), and $486 \mathrm{~g}$ (device weight with cable and connector off the scale) (Figure 1). Descriptions of the CFTAH's parameters and design features have previously been detailed. ${ }^{10}$

The study protocol was approved by Cleveland Clinic's Institutional Animal Care and Use Committee, and the animals received humane care in compliance with the Guide for the Care and Use of Laboratory Animals and institutional guidelines.

\section{Anesthesia and Surgical Techniques}

A standard protocol for premedication and anesthesia was implemented. For premedication, animals were given atropine $(0.15 \mathrm{mg} / \mathrm{kg}$ intramuscularly), ketamine ( $5 \mathrm{mg} / \mathrm{kg}$ intravenously), and inhaled $5 \%$ isoflurane before intubation. After intubation, the gastric tube was placed. The anesthetized animal was situated using an Olympic Vac-Pac (Natus Medical Inc, San Carlos, Calif) in the supine position for median sternotomy or left lateral decubitus position for a right thoracotomy incision.

Vascular access was obtained from the neck vessels for fluid-filled line placement. After a median sternotomy or right thoracotomy was performed, heparin $(300 \mathrm{U} / \mathrm{kg})$ was administered for systemic anticoagulation. The cannulation for cardiopulmonary bypass (CPB) was established by arterial line inserted in the carotid artery and through bicaval venous return. Once CPB was initiated, the hemiazygos vein was tied off. The operation was performed at hypothermia of $32^{\circ} \mathrm{C}$. The aorta and pulmonary artery were crossclamped together. Both ventricles were resected, and the atrioventricular annuli were trimmed and reinforced with polytetrafluoroethylene strips (Figure 2, A). Subsequently, the left and right atrial inflow cuffs were sutured to the reinforced left atrial stumps and tested for leaks (Figure 2, B). The aorta and pulmonary artery were dissected, crossclamped separately, and trimmed. Both vessels were then sutured to the custom-made polyethylene terephthalate grafts. The primed CFTAH was connected to the proper inflow and outflow ports after the passive deairing was performed (Figure 2, $C$ and $D$ ). The pump motor cable was exteriorized through the chest. The CFTAH was started at a low speed (2400 rpm) with the aortic crossclamp being simultaneously removed. CPB flow was decreased and stopped. Three pressure lines (left atrial pressure [LAP], right atrial pressure [RAP], and pulmonary arterial pressure) were exteriorized through the left chest. Two $32 \mathrm{~F}$ chest tubes were placed, and the chest was closed.

\section{Postoperative Care and Monitoring}

After surgery, animals were transferred to a chronic care unit and maintained in cages with continuous (hourly) monitoring of pump and physiologic parameters for the full duration of the study. Antibiotics were given for the first postoperative 7 days. Probiotic paste was given for a few days postoperatively until regular bowel movement was restored. Systemic and pulmonary vascular resistance was controlled with nitroprusside early after surgery. A continuous intravenous drip of heparin was administered in earlier experiments as an early postoperative anticoagulation therapy with activated clotting times maintained at 1.2 times baseline. In the latter case series, C13-C17, the CFTAH was run without any type of anticoagulation for the duration of the study except for a bolus injection of heparin (500 U/ $\mathrm{kg}$ ) before the animals were put to death. Diuretics were used throughout the studies as necessary. Water restriction (5-9 L/day) was applied in some cases (C15-C17). Serial blood samples were collected to detect signs of infection, bleeding, coagulopathy, renal or hepatic dysfunction, or hemolysis. Intensive wound care was provided to prevent potential contamination or dehiscence. The durations in this study series $(n=17)$ were intended to be 14 days ( $\mathrm{C} 01$ and $\mathrm{C} 02), 30$ days (C03-C15), and 90 days (C16 and C17). 


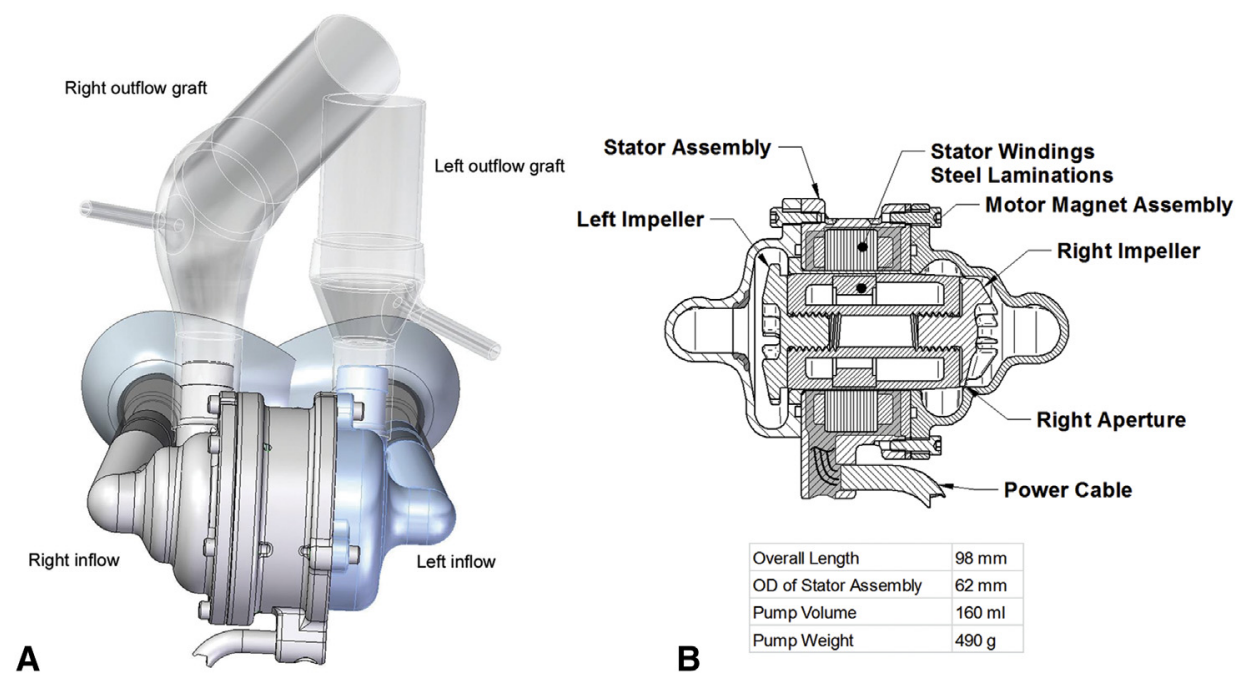

FIGURE 1. Schematic rendering of Cleveland Clinic continuous-flow total artificial heart pump. A, Atrial inflow and outflow configuration. B, Crosssection of the pump. $O D$, Outer diameter.

\section{Necropsy}

At the completion of each study, the animal was sacrificed after full heparinization (500 U/kg bolus injection), and a thorough necropsy was performed. Thrombus in/on the pump, potential infection (local or systemic), neoepithelialization of conduit surfaces, bleeding, and thromboembolism to the major organs were evaluated. Macroscopic examination included opening all major branches of the arterial system to the common iliac artery, gross examination followed by $1.5-\mathrm{cm}$ sectioning of the lungs, kidneys, liver, spleen, adrenal glands, and pancreas, gross examination of the digestive tract for signs of hemorrhage or infarction, and histology of all samples. Postexplant analysis of pump and tissue-contacting surfaces at the device was performed.
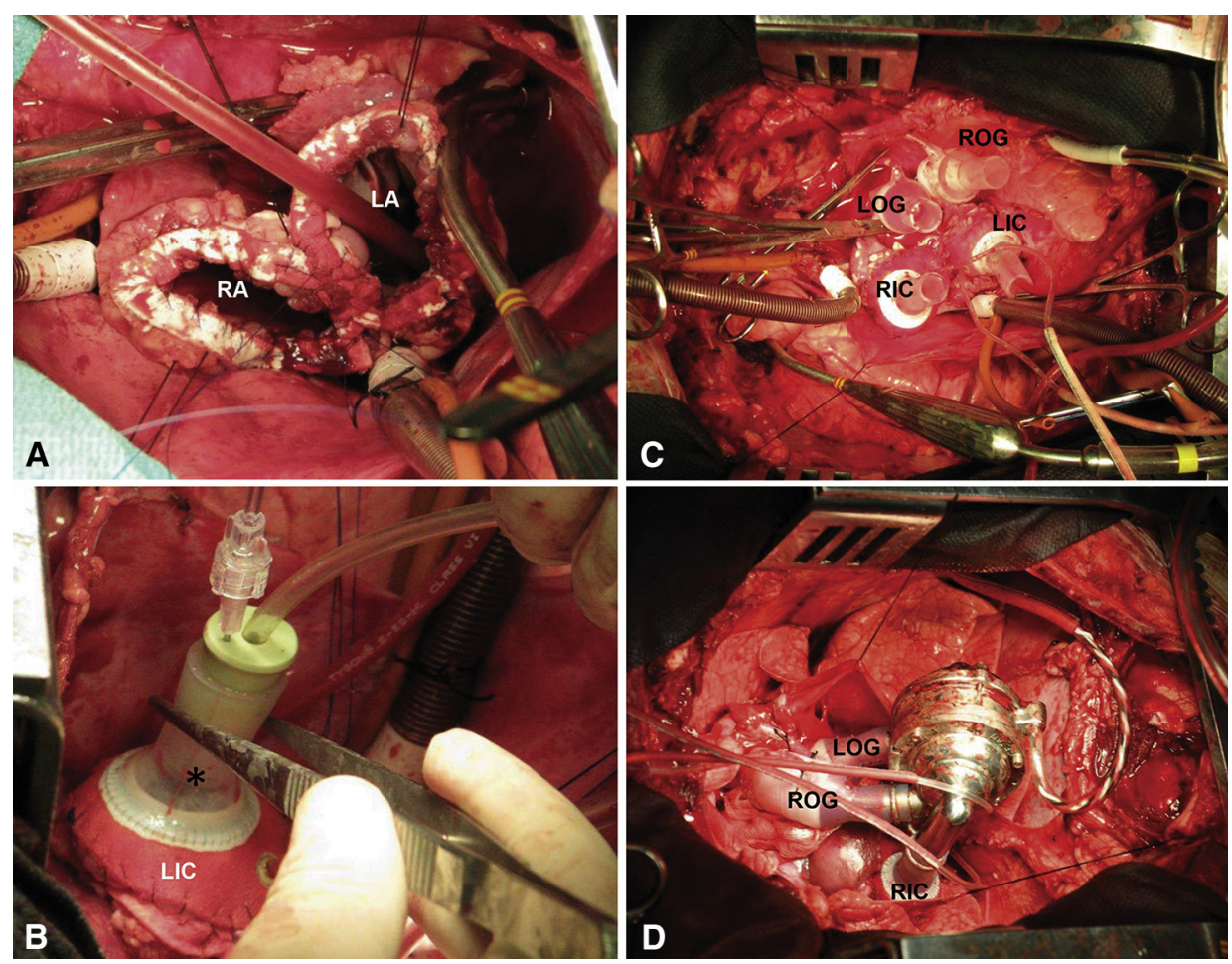

FIGURE 2. A, The operative techniques. Both atrial stumps are reinforced with polytetrafluoroethylene strips. B, Right atrial cuff is sutured and a designated tester $(*)$ is used to check anastomotic competence. C, All 4 (inflow and outflow) conduits are in place. D, Continuous flow total artificial heart is deaired and connected to its inflow and outflow ports. $R A$, Right atrium; $L A$, left atrium; $L O G$, left outflow graft; $R O G$, right outflow graft; $L I C$, left inflow cuff; $R I C$, right inflow cuff. 


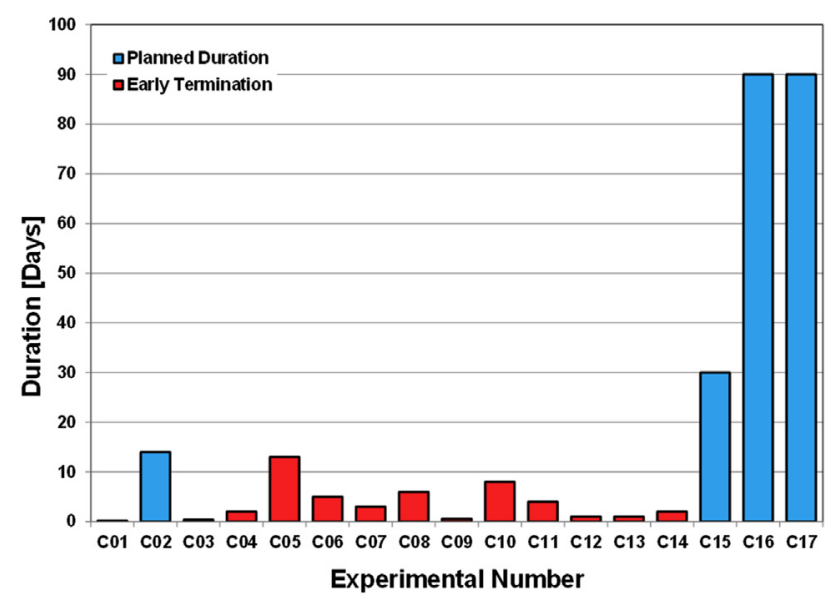

FIGURE 3. Continuous-flow total artificial heart implant durations.

\section{RESULTS}

\section{Postoperative Course and Outcomes}

The first series of 14 experiments (C01-C14) were terminated at different durations. Of these, 1 experiment was terminated at the planned duration of 14 days (C02). The last 3 cases were planned for 30-day (C15) and 90-day (C16 and C17) chronic support; these were all completed at the planned durations. The experiment durations per study interval are shown in Figure 3. No anticoagulants or thrombolytic agents were used in the last 6 cases. The first case (C01) was terminated soon after surgery due to severe respiratory failure. Three cases $(\mathrm{C} 03, \mathrm{C} 07$, and $\mathrm{C} 10)$ were terminated due to internal bleeding. In $\mathrm{C} 07$, internal bleeding occurred due to an accident (inadvertent pressure line withdrawal during exercise on postoperative day [POD] 3). Two cases were terminated due to postoperative bowel dysfunction (C05 on POD 13 and C06 on POD 5). Hemolysis was encountered $(n=2)$ due to depositions on the journal bearing in C08 (POD 6) and C11 (POD 4). Failure of a controller chip caused the pump to stop in 1 case (C14) on POD 2. Other issues caused by intraoperative complications led to neurologic deficit $(\mathrm{n}=2)$ in $\mathrm{C} 04$ and $\mathrm{C} 09$. Hypooxygenation caused by failure of CPB parameters terminated 1 case (C12) on POD 1. Anatomic abnormality of the aorta caused intraoperative hypoperfusion in 1 case $(\mathrm{C} 13) .{ }^{11}$ The last 6 implants with our improved pump design after implementing geometry changes in the journal bearing (a shorter motor allowed a $20 \%$ reduction in the overall bearing length) showed no chronic hemolysis.

TABLE 1. The pump and hemodynamic parameters in chronic experiments

\begin{tabular}{lccccc}
\hline $\begin{array}{c}\text { Pump speed, } \\
\text { krpm }\end{array}$ & $\begin{array}{c}\text { Pump } \\
\text { flow, L/min }\end{array}$ & $\begin{array}{c}\text { Power, } \\
\text { W }\end{array}$ & $\begin{array}{c}\text { AoP, } \\
\mathbf{m m} \mathbf{~ H g}\end{array}$ & $\begin{array}{c}\text { LAP, } \\
\mathbf{m m} \text { Hg }\end{array}$ & $\begin{array}{c}\text { RAP, } \\
\mathbf{m m ~ H g}\end{array}$ \\
\hline $3.0 \pm 0.1$ & $7.4 \pm 0.7$ & $12.9 \pm 1.3$ & $103 \pm 7$ & $16 \pm 3$ & $17 \pm 3$ \\
\hline$A o P$, Arterial pressure; $L A P$, left atrial pressure; & $R A P ;$ right atrial pressure.
\end{tabular}

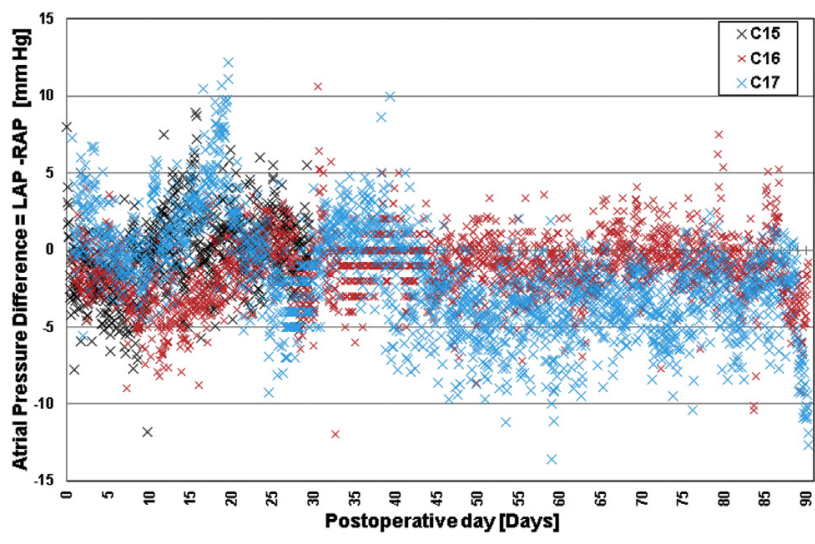

FIGURE 4. Atrial pressure differences in the 3 longest-surviving cases (ie, C15, C16, and C17). LAP, Left atrial pressure; RAP, right atrial pressure.

All 17 experiments demonstrated good hemodynamic performance of CFTAH (Table 1). The postoperative course differed in each animal as described above, in part as a consequence of intraoperative complications, or as technical issues that were encountered during this program.

The following data are from the 3 most recently implanted animals (C15-C17). The animals remained healthy throughout the planned durations with good appetite and gained body weight of $0.44 \pm 0.15 \mathrm{~kg} /$ day $(1.0 \pm 0.3 \mathrm{lb} /$ day $)$, which is typical for healthy calves. Stable hemodynamics were maintained, and the pump's self-regulating performance was confirmed in vivo with the majority of atrial pressure difference (LAP-RAP) within -10 to $+5 \mathrm{~mm} \mathrm{Hg}$ (Figure 4). Pump flow and motor current were stable with no power elevations or mechanical failure (Figures E1 and E2). The hematocrit decreased to $22.5 \% \pm 4.8 \%$ on POD $7(\mathrm{n}=3)$ but returned to $28.2 \% \pm 5.6 \%$ on POD 30 $(\mathrm{n}=3)$ without any blood transfusion after POD 8 and remained stable up to $27.2 \% \pm 1.3 \%$ on POD $90(\mathrm{n}=2)$ (Figure 5). Plasma free hemoglobin values were within range $(2.7 \pm 0.9 \mathrm{mg} / \mathrm{dL}$ on POD 30 and $11.7 \pm 13.4 \mathrm{mg} / \mathrm{dL}$ on POD 90), excluding significant hemolysis. Total protein and albumin values decreased to $3.8 \pm 0.7 \mathrm{mg} / \mathrm{dL}$ and $2.2 \pm 0.3 \mathrm{~g} / \mathrm{dL}$ on POD 3, respectively, but returned to $5.8 \pm 0.3$ and $2.9 \pm 0.5 \mathrm{~g} / \mathrm{dL}$ by POD 90 , respectively, which suggested adequate nutrition and good general physical conditions. Blood urea nitrogen $(9.6 \pm 5.7 \mathrm{mg} / \mathrm{dL})$, creatinine $(0.5 \pm 0.1 \mathrm{mg} / \mathrm{dL})$, and total bilirubin $(0.3 \pm 0.2 \mathrm{mg} / \mathrm{dL})$ values remained normal throughout the experiment. The activated clotting time values remained low (average, $244 \pm 32$ seconds).

\section{Necropsy Findings of 30- and 90-Day Animals (C15-C17)}

The necropsy revealed the rotor, stator bore, and both pump housings free of thrombus or depositions in any of 


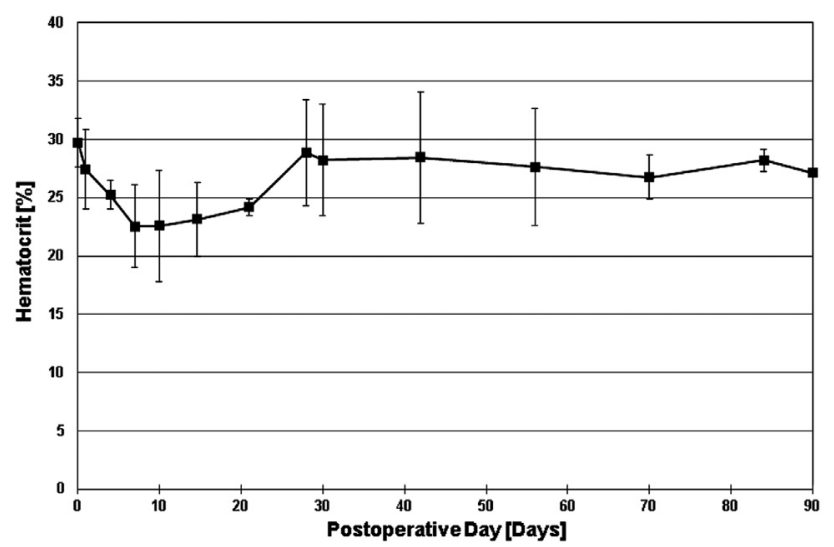

FIGURE 5. Hematocrit changes in the 3 longest-surviving cases (ie, $\mathrm{C} 15$, C16, and C17).

these 3 animals. Some depositions were observed at the junctions between the metal fitting and the silicone tubing at the inflow and outflow connections, where there are some gaps. In 1 case (C17), the pump and both outflow grafts were inspected using a miniature high-definition camera before explant and device disassembly. ${ }^{12}$ The buildup of ingrowth material at the right outflow junction in C17 had a "cauliflower" configuration and extended into the silicone port, obstructing $70 \%$ to $75 \%$ of the right outflow orifice. This was the cause of relatively low LAP compared with RAP during the final 2 days of this experiment (Figure 4). The right pump impellers caught a thrombus in $\mathrm{C} 16$ and $\mathrm{C} 17$, most likely originating at the catheter tip placed in the jugular vein. With understanding that no anticoagulation was used, these findings were not a surprise.

No thrombi or emboli were detected macro- or microscopically in any internal organs, and there were no signs of organ congestion. There were limited areas of ischemic discoloration in the renal cortical zone in 1 animal (C17); the cause of these ischemic changes was unidentifiable at histology.

\section{DISCUSSION}

Our series of in vivo single-piece CFTAH experiments has demonstrated desired hemodynamic performance and pump operation within the design specifications. No pump failures were encountered. The improved pump design in 6 animals showed no chronic hemolysis. One animal achieved the intended 30-day duration. Two animals achieved intended 90-day duration. Both median sternotomy $(\mathrm{n}=9)$ and right thoracotomy $(\mathrm{n}=8)$ surgical access techniques were evaluated in this study series. The surgical access for the longest-surviving cases (C15, $\mathrm{C} 16$, and $\mathrm{C} 17)$ was established through full median sternotomy incision. Anticoagulation was not used postoperatively. All longest-surviving cases showed acceptable biocompatibility with no organ thromboembolism.
The variability of complications that occurred during surgeries and the postimplant course suggest the multifactorial range of physiologic and technical issues that may influence postoperative survival and outcomes. Most of the issues that occurred during this developmental study indicated that specific design improvements were critical. Surgical techniques underwent substantial modifications, which improved survival. An unexpected device controller chip issue that caused the pump to stop indicated the necessity of stricter engineering pretesting, development of troubleshooting protocols, and better device quality control. The CFTAH was set in fixed speed mode with $15 \%$ speed modulation in all studies, which limits our current knowledge on possible implications on physiologic parameters and animal recovery. The conditions fully regulated by automatic speed control should be tested in the future. Future practical device improvements will involve permanent, hermetic sealing of the rotor magnet to eliminate corrosion, and the transition from a fabricated to a manufactured device. To eliminate the gaps at the junctions, the mold for the conduits will be reworked to fit more snugly with the pump.

Research into TAH devices began in the United States in 1963 under the impetus of Congress. The studies soon encountered myriad difficulties related to biocompatibility, autoregulation, device dimensions, practicality of implant and postimplant lifestyle, energy delivery, and long-term durability. Significant advances have been made in our understanding of the progression and pathophysiology of HF since the initial conceptualization of TAHs using the mechanical device from the laboratory of Willem Kolff. Advanced support systems can be implanted relatively earlier in patients with end-stage HF, with the perceived advantages of promoting ventricular remodeling and thus potentially reversing the severity of HF. In the 21 st century, TAHs are used in patients with end-stage HF to replace cardiac function so that adequate viable perfusion can be restored. Experience with the available versions of volume-displacement TAHs has been encouraging when the TAH is used as a bridge-to-transplant in this subset of patients. However, clinical experience with TAH as a destination therapy has thus far been limited.

Two CF pumps have been used in our institution for biventricular support. ${ }^{13}$ The successful implantation of extracorporeal centrifugal pumps indicates the potential of the $\mathrm{CF}$ environment on animal physiology. The first use of an implantable CFLVAD for total heart replacement was reported by Frazier and colleagues ${ }^{14}$ in a calf experiment of 20 days' duration. Two Jarvik 2000 FlowMaker pumps (Jarvik Heart, Inc, New York, NY) were used for this implant. It has been suggested that at a fixed rotational speed, flow increases with rising pump inlet pressures and decreases with falling ones; however, at what extent the preload effect is minimal may still be questionable. This device regulation may allow a TAH constructed from 2 rotary pumps to 
maintain some degree of autonomous balance between the systemic and pulmonary circulations under various physiologic conditions versus pulsatile, volume-displacement TAHs. Since 2005, the Texas Heart Institute has been active in developing their TAH system with 2 CF pumps, having implanted that system in 65 calves, 2 of which survived for 90 days (mean, 24 days). ${ }^{15,16}$ Another team ${ }^{17}$ recently reported encouraging data for their initial clinical experience with dual HeartWare HVAD (HeartWare Inc, Framingham, Mass) CF LVADs. More complex CFTAH control schemes and/or pressure/flow sensors will likely be needed to provide safe and effective cardiac replacement with dual CFLVAD pumps for the chronic treatment of biventricular HF. Matching right- and left-side pump outputs while balancing atrial pressures is more difficult for CF devices than for their pulsatile TAH predecessors when the native ventricle is not available to compensate for flow and pressure mismatches.

An Australian team of inventors ${ }^{18}$ has joined with the Texas Heart Institute for device development and in vivo studies to evaluate a similar single-pump CFTAH for total heart replacement (BiVacor BV Replace; BiVacor Pty Ltd, Wilston, Australia). This device requires substantial input from sensors because its rotating element requires electromagnetic suspension that must be actively positioned in the pump housing to balance flows. The BiVacor system requires almost twice the power of our CFTAH ( $19 \mathrm{vs} 10 \mathrm{~W}$ at the $6 \mathrm{~L} / \mathrm{min}$ and mean arterial pressure of $100 \mathrm{~mm} \mathrm{Hg}$ condition). ${ }^{19}$

Despite the major advances that have been achieved with prolonged duration of CFTAH support and due to clinical unavailability of a dedicated single-piece CFTAH, the compensatory adaptability of existing devices for unmet needs is likely to remain an unresolved issue for years to come. Adaptations of various LVADs for TAH may continue. However, hope for the solution lies in devices specifically designed for TAH application that will be undergoing validation until a true clinical solution becomes available.

The limitations in this study include that the number of successful experiments ( $\geq 30$ days) is only 3 , biocompatibility with low flow condition was not validated, and automatic speed control mode was not tested. Our current experience with single-piece continuous flow pumps suggests the necessity of further evaluation of this promising technology and its effects on physiologic parameters.

\section{CONCLUSIONS}

In this report we present an experimental study series in 17 calves implanted with the Cleveland Clinic CFTAH device. This is the first report of successful 90-day implants with a single-piece CF artificial heart. Two animals achieved this intended duration. The implementation of this project and achievement of this important milestone suggests that single-piece, autoregulated, and sensorless devices have the potential to further develop into a valid clinical option for patients with heart failure.

\section{Conflict of Interest Statement}

D.H., L.A.R.G., and B.K. are coinventors of the device. The technology was licensed to Cleveland Heart, Inc, a Cleveland Clinic spin-off company. All other authors have nothing to disclose with regard to commercial support.

The authors thank Raymond Dessoffy and Stephen Benefit, Department of Biomedical Engineering; Perfusion Team Leaders Patrick Grady and Martin Sinkewic; Jianzhong Cang of the Lerner Research Institute; Dr Richard Morton, Dr Timothy Myshrall, Jennifer Veillette, Sarah Morales, Amanda Stewart, and Glen Stevenson, Biological Resources Unit; Jackie Kattar and Laura Konczos, Cleveland Clinic Innovations; and Mark Goodin, SimuTech Group, for their effort, valuable help, and technical assistance.

\section{References}

1. Go AS, Mozaffarian D, Roger VL, Benjamin EJ, Berry JD, Borden WB, et al. Executive summary: heart disease and stroke statistics-2013 update: a report from the American Heart Association. Circulation. 2013;127:143-52.

2. McMurray JJ, Petrie MC, Murdoch DR, Davie AP. Clinical epidemiology of heart failure: public and private health burden. Eur Heart J. 1998;19(Suppl P): P9-16.

3. Braunwald E. Research advances in heart failure: a compendium. Circ Res. 2013; 113:633-45.

4. Garbade J, Bittner HB, Barten MJ, Mohr FW. Current trends in implantable left ventricular assist devices. Cardiol Res Pract. 2011;2011:290561.

5. Wever-Pinzon O, Drakos SG, Kfoury AG, Nativi JN, Gilbert EM, Everitt M, et al. Morbidity and mortality in heart transplant candidates supported with mechanical circulatory support: is reappraisal of the current United network for organ sharing thoracic organ allocation policy justified? Circulation. 2013;127:452-62.

6. Moazami N, Fukamachi K, Kobayashi M, Smedira NG, Hoercher KJ, Massiello A, et al. Axial and centrifugal continuous-flow rotary pumps: a translation from pump mechanics to clinical practice. J Heart Lung Transplant. 2013; 32:1-11.

7. Kirklin JK, Naftel DC, Pagani FD, Kormos RL, Stevenson LW, Blume ED, et al. Sixth INTERMACS annual report: a 10,000-patient database. J Heart Lung Transplant. 2014;33:555-64.

8. Drakos SG, Janicki L, Horne BD, Kfoury AG, Reid BB, Clayson S, et al. Risk factors predictive of right ventricular failure after left ventricular assist device implantation. Am J Cardiol. 2010;105:1030-5.

9. Fukamachi K, Horvath DJ, Massiello AL, Fumoto H, Horai T, Rao S, et al. An innovative, sensorless, pulsatile, continuous-flow total artificial heart: device design and initial in vitro study. J Heart Lung Transplant. 2010;29:13-20.

10. Kobayashi M, Horvath DJ, Mielke N, Shiose A, Kuban B, Goodin M, et al. Progress on the design and development of the continuous-flow total artificial heart. Artif Organs. 2012;36:705-13.

11. Karimov JH, Sunagawa G, Such KA, Sale S, Golding LA, Moazami N, et al. Anatomy of the bovine ascending aorta and brachiocephalic artery found unfavorable for total artificial heart implant. JArtif Organs. June 24, 2015 [Epub ahead of print].

12. Karimov JH, Horvath D, Sunagawa G, Byram N, Moazami N, Golding LA, et al. Post-explant visualization of thrombi in outflow grafts and their junction to a continuous-flow total artificial heart using a high-definition miniaturized camera. J Artif Organs. May 5, 2015 [Epub ahead of print].

13. Golding LR, Jacobs G, Murakami T, Takatani S, Valdes F, Harasaki H, et al. Chronic nonpulsatile blood flow in an alive, awake animal 34-day survival. Trans Am Soc Artif Intern Organs. 1980;26:251-5.

14. Frazier OH, Tuzun E, Cohn WE, Conger JL, Kadipasaoglu KA. Total heart replacement using dual intracorporeal continuous-flow pumps in a chronic bovine model: a feasibility study. ASAIO J. 2006;52:145-9.

15. Cohn WE, Handy KM, Parnis SM, Conger JL, Winkler JA, Frazier OH. Eightyear experience with a continuous-flow total artificial heart in calves. ASAIO J. 2014;60:25-30. 
16. Cohn WE, Winkler JA, Parnis S, Costas GG, Beathard S, Conger J, et al. Ninetyday survival of a calf implanted with a continuous-flow total artificial heart. ASAIO J. 2014;60:15-8.

17. Strueber M, Meyer AL, Malehsa D, Haverich A. Successful use of the HeartWare HVAD rotary blood pump for biventricular support. J Thorac Cardiovasc Surg. 2010;140:936-7.

18. Timms D, Fraser J, Hayne M, Dunning J, McNeil K, Pearcy M. The BiVACOR rotary biventricular assist device: concept and in vitro investigation. Artif Organs. 2008;32:816-9.
19. Kleinheyer M, Timms DL, Greatrex NA, Masuzawa T, Frazier OH, Cohn WE Pulsatile operation of the BiVACOR TAH - Motor design, control and hemodynamics. Conf Proc IEEE Eng Med Biol Soc. 2014;2014:5659-62.

Key Words: total artificial heart, mechanical circulatory support, continuous flow, pumps, heart-assist, biocompatibility testing

Readers who found these articles interesting may also like to read the following papers found in recent and future issues of our sister publications, Seminars in Thoracic and Cardiovascular Surgery and Operative Techniques in Thoracic and Cardiovascular Surgery!

\section{Cardiothoracic Transplantation and Mechanical Circulatory Support}

State of the Art: The State of the Art in Corporeal Membrane Oxygenation. Steve K. Singh. Semin Thorac Cardiovasc Surg 2015; Spring; 27(1):17-23.

Techniques for lung procurement following donation after circulatory death. Pankaj Saxena. Oper Tech Thorac Cardiovasc Surg 2014; Autumn; 19(3):380-393.

Techniques for venoarterial ECMO support and conversion to temporary left ventricular Assist Device. Ashok Babu. Oper Tech Thorac Cardiovasc Surg 2014; Autumn; 19(3):253-394.

Non-sternotomy approaches to left ventricular assist device placement. Simon Maltais. Oper Tech Thorac Cardiovasc Surg 2014; Autumn; 19(3):276-291.

Non-Sternotomy Approaches to Left Ventricular Assist Device Placement: Combined Left Subcostal - Right Mini-Thoracotomy Technique. Anelechi Anyanwu. Oper Tech Thorac Cardiovasc Surg 2014; Autumn; 19(3):254-275.

Ex Vivo Lung Perfusion. Marcelo Cypel. Oper Tech Thorac Cardiovasc Surg 2014; Winter, 19(4):433-442.

Subcostal Approach to Replacement of a HeartMate II Device: Indications and Technique. Nader Moazami. Oper Tech Thorac Cardiovasc Surg 2014; Winter, 19(4):443-453. 


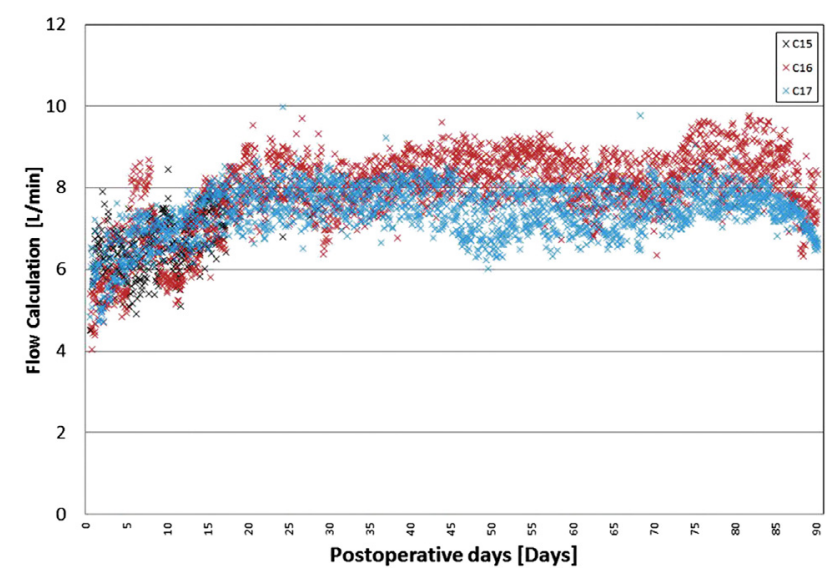

FIGURE E1. Calculated flow (L/min) in the 3 longest-surviving cases (ie, C15, C16, and C17).

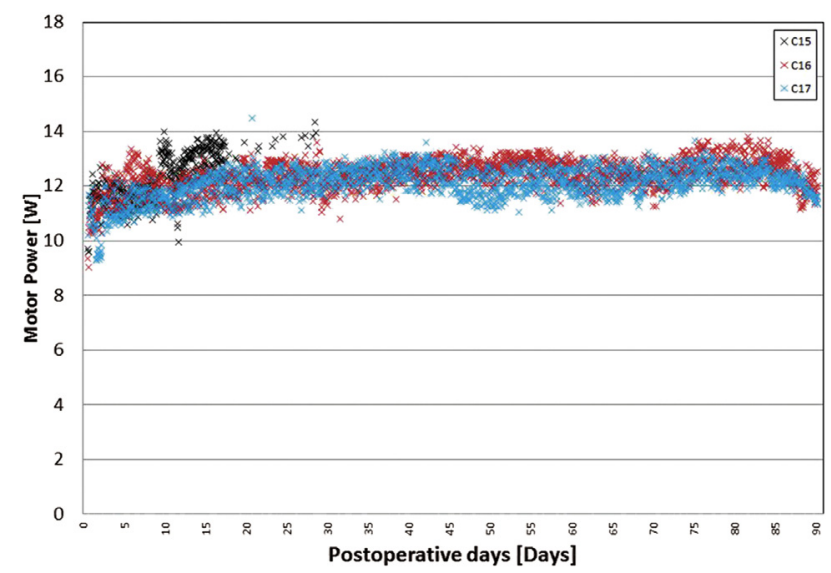

FIGURE E2. Motor power (W) in 3 longest-surviving cases (ie, C15, C16, and C17). 